\section{Unconscious by any other name...}

\author{
Derek J. O’Brien
}

In their Review (Neural bases of the nonconscious perception of emotional signals. Nature Rev. Neurosci. 11, 697-709 (2010)) ${ }^{1}$, Tamietto and de Gelder misunderstand the term 'unconscious' to be "rooted in the psychoanalytic tradition" and to refer only to mental processes that are actively repressed as well as pathological. The descriptive meaning of 'unconscious' (for which the word has been in use over 3 centuries) they claim as the meaning of their new term: 'non-conscious'. This ambitious replacement of 'unconscious' with 'non-conscious' seems to be in order to establish a dichotomy between mental processes understood by psychoanalysis and those understood by neuroscience.

The authors are right to point out that there are important differences between psychoanalysis and neuroscience ${ }^{2}$. If both fields observe mental processes that are "not accessible to consciousness", it does not necessarily follow that they are observing the same processes. But it would also be an error to assume that mental processes are unrelated simply because they are observed from different perspectives. Evidence for neural bases of "the existence in mental life of unconscious processes in general"' raises the question: are these findings in the nervous system related to unconscious processes observed in psychoanalysis?

Although connections between the two fields may be difficult to recognize now, it is important to remember that Freud, at the end of the nineteenth century, began developing psychoanalytic observation out of a neurological approach ${ }^{4,5}$. In his early attempt to construct a neural model that could explain the organization he observed in his patients' thoughts, he documented a clinical case that is relevant to the question above ${ }^{6}$.
Emma had a fear of going into shops by herself. As an initial explanation she told Freud a memory of entering a shop at 12 years old, perceiving two shop assistants laughing together, and of running away "in some kind of affect of fright." ${ }^{6}$ She went on to recall they were laughing at her clothes.

Freud noted that this initial story didn't explain the intensity of her emotional response. Emma brought up another memory of an earlier event (Scene II), which had not come consciously to mind at the time of the later event (Scene I): at eight years old, "she had gone into a small shop to buy some sweets, and the shopkeeper had grabbed at her genitals through her clothes."

An "associative link ... was provided by the laughing: the laughing of the shop-assistants had reminded her of the grin with which the shopkeeper had accompanied his assault."

Freud explained: "In the shop the two assistants were laughing; this laughing aroused (unconsciously) the memory of the shopkeeper. Indeed, the situation had yet another similarity [to the earlier one]: she was once again in a shop alone. Together with the shopkeeper she remembered his grabbing through her clothes ... With this anxiety, she was afraid that the shop-assistants might repeat the assault, and she ran away." ${ }^{\prime \prime}$

The clinical material is simplified here to highlight elements that can be understood in Pavlovian terms. Rodent studies of acoustic startle and classical conditioning led to the discovery of a subcortical pathway for processing sensory experiences involved in fear response $e^{7,8}$. Much of the research reviewed by Tamietto and de Gelder has been influenced by the hypothesis that similar pathways in the human brain process

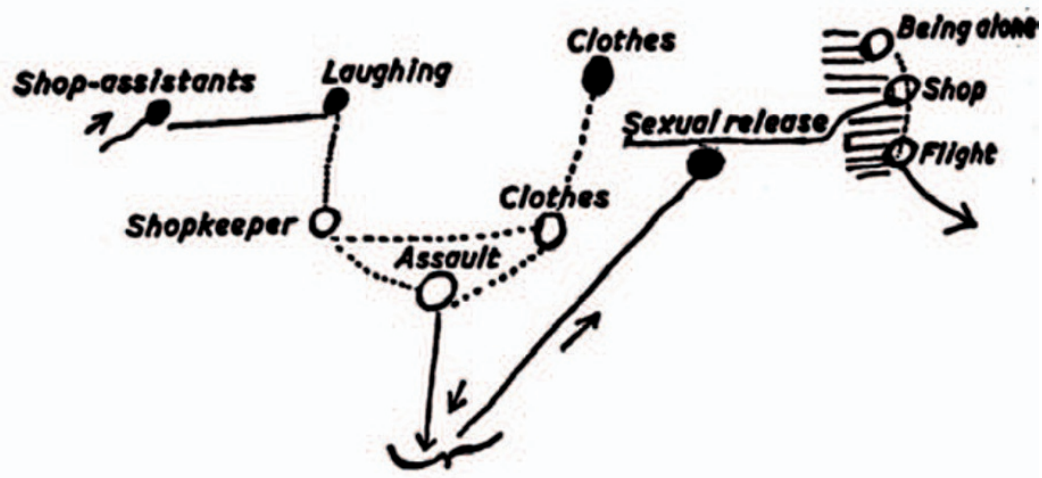

Figure 1 | Representation of separate memory processes in a clinical subject, from Freud's Project for a scientific psychology (1895). Figure is reproduced, with permission, from REF. 6 (C) (1973) Paterson Marsh Ltd. emotional stimuli outside of conscious awareness owing to their bypassing the cortex ${ }^{9}$.

LeDoux ${ }^{10}$ elaborates on this hypothesis to explain how - owing to implicit and explicit memory systems "operating in parallel to give rise to independent memory functions" - a stimulus might cause someone to reexperience the fear associated with an earlier trauma without consciously remembering the event. Because of this, he speculates, "you may find yourself in the throes of an emotional state that exists for reasons you do not quite understand." 10

Along the same line (but from the opposite direction) Freud considers in Emma, "that two kinds of $\psi$ (memory) processes are mixed up together here, that the memory of Scene II (shopkeeper) occurred in quite a different state from the other one." 6 Freud represents this with an illustration (FIG. 1), in which "the blacked-in ideas are perceptions which are also remembered" and "nothing of the process (represented underneath) entered consciousness except the element clothes." ${ }^{\text {" }}$

Freud (proceeding from the psychoanalytic exploration of a woman's fear) and LeDoux (proceeding from the study of neural pathways mediating fear conditioning in the rat) come to the same hypothesis: that the human brain contains a neural system involved in the memory of fear, which is separate from that involved in the conscious recall of an event. Rather than the departure of neuroscience from psychoanalytic conceptualizations described by Tamietto and de Gelder, the discovery in humans of a subcortical pathway for processing fearful aspects of sensory experience would provide an important link between psychoanalytic and neuroscientific observations of unconscious mental processes.

Derek J. O'Brien is at the Department of Psychiatry and Behavioral Sciences, and the Psychoanalytic Institute at Emory University, Atlanta, Georgia 30322, USA.

e-mail:dobri01@emory.edu

doi:10.1038/nrn2889-c1

Tamietto, M $\delta$ de Gelder B. Neural bases of the nonconscious perception of emotional signals. Nature Rev. conscious perception of emotional

Levy, S. T. \& Nemeroff, C. B. From psychoanalysis to neurobiology. National Forum 73, 18 (1993). Freud, S. New Introductory Lectures on Psycho-Analysis Standard edn Vol. 22 1-182 (Hogarth Press, London, 1973).

Pribram, K. H. A Century of Progress? Ann. NY Acad. Sci. 843, 11-19 (1998)

Schott, G. D. Freud's Project and its diagram: anticipating the Hebbian synapse. J. Neurol. Neurosurg. Psychiatry 82, 122-125 (2011) Freud, S. Project for a Scientific Psychology (1895) Vol. 1, 295-387 (Hogarth Press, London, 1973) efferent projections of the medial geniculate nucleus mediate emotional responses conditioned to acoustic mediate emotional responses conditioned
stimuli. J. Neurosci. 4, 683-698 (1984).

8. Davis, M., Gendelman, D., Tischler, M. \& Gendelman, P. A primary acoustic startle circuit: lesion and stimulation studies. J. Neurosci. 2, 791-805 (1982).

Pessoa, L. \& Adolphs, R. Emotion processing and the amygdala: from a 'low road' to 'many roads' of evaluating biological significance. Nature Rev. Neurosci. 11, 773-783 (2010).

10. LeDoux, J. E. The Emotional Brain: The Mysterious Underpinnings of Emotional Life (Simon and Schuster. New York, 1998). 